\title{
Slow Strain Rate Testing for Hydrogen Embrittlement Susceptibility of Alloy 718 in Substitute Ocean Water
}

\author{
M.P. LaCoursiere, D.K. Aidun, and D.J. Morrison
}

\author{
(Submitted January 29, 2017; in revised form April 2, 2017; published online April 12, 2017)
}

\begin{abstract}
The hydrogen embrittlement susceptibility of near-peak-aged UNS N07718 (Alloy 718) was evaluated by performing slow strain rate tests at room temperature in air and substitute ocean water. Tests in substitute ocean water were accomplished in an environmental cell that enabled in situ cathodic charging under an applied potential of $-1.1 \mathrm{~V}$ versus SCE. Some specimens were cathodically precharged for 4 or 16 weeks at the same potential in a $3.5 \mathrm{wt} . \% \mathrm{NaCl}$-distilled water solution at $50^{\circ} \mathrm{C}$. Unprecharged specimens tested in substitute ocean water exhibited only moderate embrittlement with plastic strain to failure decreasing by about $20 \%$ compared to unprecharged specimens tested in air. However, precharged specimens exhibited significant embrittlement with plastic strain to failure decreasing by about $70 \%$. Test environment (air or substitute ocean water with in situ charging) and precharge time (4 or 16 weeks) had little effect on the results of the precharged specimens. Fracture surfaces of precharged specimens were typical of hydrogen embrittlement and consisted of an outer brittle ring related to the region in which hydrogen infused during precharging, a finely dimpled transition zone probably related to the region where hydrogen was drawn in by dislocation transport, and a central highly dimpled ductile region. Fracture surfaces of unprecharged specimens tested in substitute ocean water consisted of a finely dimpled outer ring and heavily dimpled central region typical of ductile fracture.
\end{abstract}

Keywords hydrogen embrittlement, nickel-based superalloy, slow strain rate testing

\section{Introduction}

The nickel-based alloy UNS N07718 (Alloy 718) has been used for many years in aircraft turbine engine applications such as compressor blades, compressor disks, turbine disks, and fasteners because of the alloy's superior corrosion resistance and high-temperature strength (Ref 1). Strength is achieved through solid solution strengthening and the controlled precipitation of $\gamma^{\prime}\left(\mathrm{Ni}_{3} \mathrm{Al}-\right.$ fcc-type structure $)$ and $\gamma^{\prime \prime}\left(\mathrm{Ni}_{3} \mathrm{Nb}\right.$ - bcttype structure). The $\gamma^{\prime \prime}$ is the primary contributor to the strengthening (Ref 2). In addition, the microstructure frequently contains $\delta$ precipitates $\left(\mathrm{Ni}_{3} \mathrm{Nb}\right.$ - orthorhombic-type structure) and various metal carbide particles (Ref 3 ). More recently, the alloy has been used in oil and gas applications such as subsurface valves, blowout preventers, and fasteners (Ref 4, 5). In many oil field applications, Alloy 718 is used in systems that use cathodic protection to enhance corrosion resistance (Ref 6, 7). Unfortunately, the resulting electrochemical reaction causes hydrogen to be produced at the surface of the metal. This hydrogen diffuses into the metal and can cause hydrogen embrittlement.

The phenomenon of hydrogen embrittlement was first reported in 1875 by William Johnson (Ref 8) when he observed that exposure to acid caused significant embrittlement of iron. Furthermore, he observed that the process was reversible. After

M.P. LaCoursiere, D.K. Aidun, and D.J. Morrison, Department of Mechanical and Aeronautical Engineering, Clarkson University, Potsdam, NY. Contact e-mail: djm@clarkson.edu. a period of time in air, the iron recovered its original ductility (Ref 8,9$)$. Since that time, there has been a great deal of research on hydrogen embrittlement of metals and many theories have been proposed to explain the phenomenon. Recently, several review articles have been published that detail the strengths and weaknesses of the proposed mechanisms (Ref 9-11). It is generally agreed that in non-hydride forming metals, two mechanisms explain most of the observed hydrogen embrittlement behavior: hydrogen-induced decohesion (HID) (Ref 12-14) and hydrogen-enhanced localized plasticity (HELP) (Ref 15, 16).

The HID mechanism proposes that the presence of hydrogen reduces the interatomic bond strength, which leads to decohesion along certain crystallographic planes or interfaces such as grain boundaries. The decohesion leads to brittle transgranular cleavage or intergranular failure. Recent molecular dynamics simulations of iron by Wang et al. (Ref 17) predict a $37 \%$ reduction in grain boundary cohesive energy when the metal is subjected to hydrogen charging conditions that typically cause intergranular failure.

The HELP mechanism proposes that the presence of dissolved hydrogen enhances the motion of dislocations and then causes localized shearing along preferred crystallographic planes. The localized shearing leads to transgranular failure and produces a fracture surface that appears similar to conventional cleavage. The hydrogen atmosphere that forms at a dislocation alters the shape of the stress field and creates easy and hard shearing directions, thus enhancing the mobility of dislocations in the easy directions (Ref 9). Clear evidence of the ability of hydrogen to enhance dislocation mobility in various metals has been shown by TEM studies (Ref 18-22). In those studies, enhanced dislocation motion was observed during in situ TEM straining of metals in a hydrogen-containing environmental cell. The well-established concepts associated with the effects of solute atmospheres on dislocation mobility explain the strain 
rate and temperature sensitivity of many hydrogen embrittlement observations. At high plastic strain rates or elevated temperatures, the hydrogen atmosphere will not be bound to the dislocation, and the embrittlement effect of hydrogen is diminished (Ref 9).

The synergistic effects of the HID and HELP mechanisms have been described by Robertson et al. (Ref 9) and Dadfarnia et al. (Ref 11). Hydrogen-enhanced dislocation mobility causes additional dislocation interactions with microstructural features such as grain boundaries or particle-matrix interfaces. The dislocations deposit their hydrogen atmospheres at these features. The hydrogen deposition reduces the cohesive strength of the boundary or interface and leads to crack initiation.

A number of studies on hydrogen embrittlement of cathodically charged Alloy 718 have been presented. In many of these studies, the effects of microstructure, loading conditions, and cathodic charging conditions were investigated through the use of slow strain rate (SSR) testing (Ref 23, 24). In a SSR test, the specimen is loaded in tension at a very low strain rate, generally on the order of $10^{-6} \mathrm{~s}^{-1}$. Hydrogen can be introduced by cathodic charging before testing (precharged), or by performing the test in an environmental cell and charging as the specimen is loaded (in situ charged).

Fournier et al. (Ref 25) performed SSR tests on peak-aged $\left(\sigma_{\mathrm{ys}} \approx 1300 \mathrm{MPa}\right)$ Alloy 718 specimens that were either precharged for $8 \mathrm{~h}$ and tested in air or charged in situ during testing. The charging was accomplished at room temperature in a solution of $1 \mathrm{~N} \mathrm{H}_{2} \mathrm{SO}_{4}$ at a current density of $100 \mathrm{~mA} \mathrm{~cm}{ }^{-2}$. The specimens were loaded at room temperature at strain rates ranging from $5 \times 10^{-7}$ to $5 \times 10^{-3} \mathrm{~s}^{-1}$. They found that hydrogen embrittlement sensitivity increased as strain rate decreased and that the embrittlement was especially severe in the in situ charged tests. For tests accomplished in situ at the lower strain rate, the plastic elongation ratio (PER) was approximately 0.06 where PER is defined as the plastic strain at fracture in the hydrogen-charged condition divided by the plastic strain at fracture of a hydrogen-free specimen. Embrittlement was less severe in the precharged specimen where the PER was 0.71 . Similar results were reported by McCoy et al. (Ref 26).

Rezende et al. (Ref 27) performed SSR tests on Alloy 718 specimens that were heat-treated $\left(\sigma_{\mathrm{ys}} \approx 770 \mathrm{MPa}\right)$ according to API 6A718 (Ref 28). That specification details procedures that enhance the application of Alloy 718 in oil and gas applications by limiting the formation of the $\delta$ phase and specifying maximum strength and hardness levels. SSR tests were also performed on solution-annealed specimens $\left(\sigma_{\mathrm{ys}} \approx 360 \mathrm{MPa}\right)$. The SSR tests were accomplished at a strain rate of $3.2 \times 10^{-4}$ on specimens that were precharged for 21 days in $0.1 \mathrm{M}$ $\mathrm{H}_{2} \mathrm{SO}_{4}$ at a current density of $20 \mathrm{~mA} \mathrm{~cm}{ }^{-2}$. All testing and charging were accomplished at room temperature. Precharging had no effect on the yield strength of the heat-treated material, but increased the yield strength of the solution-aged material from 360 to $536 \mathrm{MPa}$. The PER for the heat-treated material was 0.54 , and for the solution-annealed material, the ratio was 0.75 .

SSR tests on Alloy 718 that had been heat-treated $\left(\sigma_{\mathrm{ys}} \approx 1000 \mathrm{MPa}\right)$ in accordance with API 6A718 were also reported by Tarzimoghadam et al. (Ref 29). In those experiments, specimens were precharged for $4 \mathrm{~h}$ in a $5 \% \mathrm{H}_{2} \mathrm{SO}_{4}$ solution containing $3 \mathrm{~g} \mathrm{~L}^{-1}$ of $\mathrm{NH}_{4} \mathrm{SCN}$, which inhibited the recombination of atomic hydrogen to molecular hydrogen. Hydrogen charging was accomplished at room temperature at a current density of $40 \mathrm{~mA} \mathrm{~cm}{ }^{-2}$. The same charging conditions were continued in situ during the SSR tests which were conducted at a strain rate of $10^{-4} \mathrm{~s}^{-1}$. The SSR tests indicated that charging had no effect on yield strength but caused significant embrittlement. The PER of the charged specimen was 0.2 .

Kagay et al. (Ref 30) performed SSR tests on Alloy 718 specimens that were near-peak-aged $\left(\sigma_{\mathrm{ys}} \approx 1006 \mathrm{MPa}\right)$, overaged $\left(\sigma_{\mathrm{ys}} \approx 769 \mathrm{MPa}\right)$, and under-aged $\left(\sigma_{\mathrm{ys}} \approx 775 \mathrm{MPa}\right)$. The heat treatments conformed to API 6ACRA (Ref 31), the successor to API 6A718, to limit the amount of $\delta$ precipitation. Additional specimens were produced under heat treatment conditions that encouraged the precipitation of the $\delta$ phase $\left(\sigma_{\mathrm{ys}} \approx 951 \mathrm{MPa}\right)$. The in situ SSR tests were accomplished at room temperature in $0.5 \mathrm{M} \mathrm{H}_{2} \mathrm{SO}_{4}$ at a charging density of $5 \mathrm{~mA} \mathrm{~cm}^{-2}$ and strain rate of $10^{-6} \mathrm{~s}^{-1}$. Significant hydrogen embrittlement was observed in all of the heat treatment conditions. The under-aged condition performed the best with a PER of 0.46 , and the high $\delta$ condition performed the worst with a PER of 0.08 . For the near-peak-aged metal, the PER was 0.12 . The authors attributed the superior performance of the under-aged material to the absence of $\delta$ precipitates at the grain boundaries.

Foroni and Malara (Ref 32) performed SSR tests on two heat treatments of Alloy 718 that produced material with $\sigma_{\mathrm{ys}} \approx 996$ and $828 \mathrm{MPa}$. The in situ SSR tests were accomplished at $40{ }^{\circ} \mathrm{C}$ in $0.5 \mathrm{M} \mathrm{H}_{2} \mathrm{SO}_{4}$ at a charging density of $5 \mathrm{~mA} \mathrm{~cm}{ }^{-2}$ and strain rate of $10^{-6} \mathrm{~s}^{-1}$. Their results were quite surprising in that there was only moderate embrittlement, and the higher strength material performed better than the lower strength material. For the higher strength material, the PER was 0.899 , and for the lower strength material, the ratio was 0.517 . While the details of the two heat treatments were not provided, the authors attributed the observed behavior to the different precipitates that formed during the two heat treatments.

To more closely duplicate the ocean environment in some oil field applications, several studies evaluated the hydrogen embrittlement susceptibility of Alloy 718 in $\mathrm{NaCl}$ aqueous solutions. Kernion et al. (Ref 33) accomplished in situ SSR tests at room temperature in a $3.5 \mathrm{wt} . \% \mathrm{NaCl}$ solution and charging potential of $-1.1 \mathrm{~V}$ relative to a saturated calomel electrode $\left(V_{\mathrm{SCE}}\right)$. Specimens with yield strengths ranging from 1259 to $854 \mathrm{MPa}$, including a high $\delta$ type, were tested at a strain rate of $4 \times 10^{-6} \mathrm{~s}^{-1}$. All the material variations exhibited limited embrittlement. PERs ranged from a low of 0.78 for the highest strength material to a relatively consistent 0.9 for the lower strength materials.

Zhang et al. (Ref 34) performed SSR testing on an Alloy 718 specimen $\left(\sigma_{\mathrm{ys}} \approx 420 \mathrm{MPa}\right)$ that was precharged for 7 days in a $1 \mathrm{~mol} \mathrm{~L}^{-1} \mathrm{NaCl}$ solution at $80{ }^{\circ} \mathrm{C}$ and charging current density of $7.7 \mathrm{~mA} \mathrm{~cm}{ }^{-2}$. The precharged specimen was then SSR tested in room temperature air at a strain rate of $10^{-6} \mathrm{~s}^{-1}$. The PER for the precharged specimen was about 0.5 .

Jothi et al. (Ref 35) performed SSR tests on solution heattreated specimens $\left(\sigma_{\mathrm{ys}} \approx 420 \mathrm{MPa}\right)$ that were precharged for 4 or 16 hours in a $3 \% \mathrm{NaCl}$ solution at room temperature and current density of $1 \mathrm{~mA} \mathrm{~cm}{ }^{-2}$. The precharged specimens were also charged in situ during the SSR tests which were performed 
Table 1 Chemical composition of Alloy 718 used for this study

\begin{tabular}{llll}
\hline $\mathrm{Fe}$ & 18.68 wt. $\%$ & $\mathrm{Cb}(\mathrm{Nb})$ & 5.14 \\
$\mathrm{Ni}$ & 52.93 & $\mathrm{Ti}$ & 0.92 \\
$\mathrm{Cr}$ & 18.37 & $\mathrm{Cu}$ & 0.04 \\
$\mathrm{Mo}$ & 2.90 & $\mathrm{Co}$ & 0.14 \\
$\mathrm{C}$ & 0.04 & $\mathrm{Al}$ & 0.59 \\
$\mathrm{Mn}$ & 0.12 & Other & 0.10
\end{tabular}

All values given in wt. $\%$
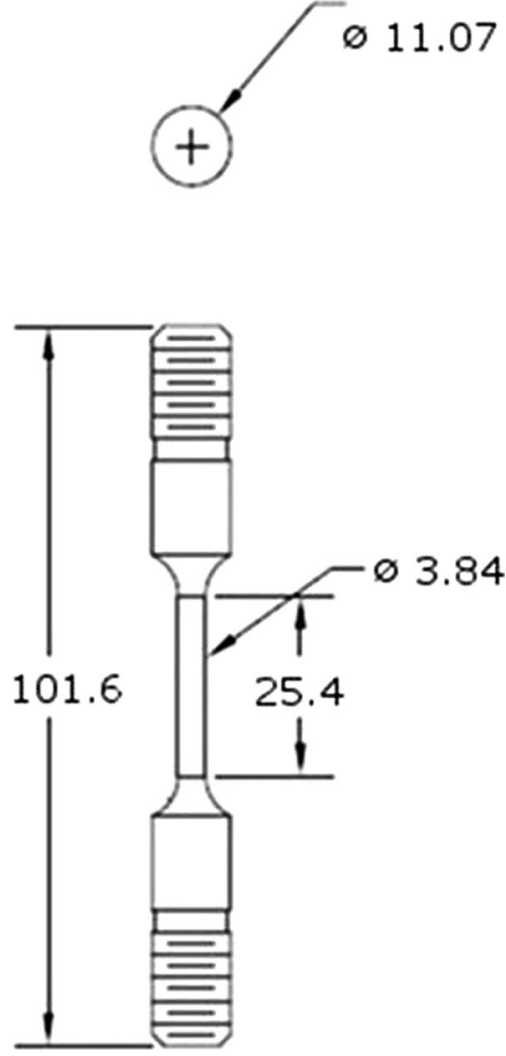

Fig. 1 Test specimen geometry. All dimensions are in $\mathrm{mm}$

at strain rates of $10^{-4}$ and $10^{-3} \mathrm{~s}^{-1}$. The results demonstrated that yield strength was not affected by the different charging and testing conditions. However, ultimate tensile strength increased and tensile ductility decreased as a result of the hydrogen charging. Embrittlement was more pronounced at the lower strain rate and longer precharge time. For the $16 \mathrm{~h}$ precharge, the PER for the specimen tested at $10^{-4} \mathrm{~s}^{-1}$ was 0.37 , and for the specimen tested at $10^{-3} \mathrm{~s}^{-1}$, the ratio was 0.76 .

SSR tests on Alloy 718 specimens that were both precharged and charged in situ were also reported by Rollins et al. (Ref 36). The alloy was heat-treated to minimize $\delta$ precipitation and resulted in a yield strength of $938 \mathrm{MPa}$. All charging was accomplished in 3.5 wt. $\% \mathrm{NaCl}$ at $4.4{ }^{\circ} \mathrm{C}$ and charging potential of $-1.05 V_{\mathrm{SCE}}$. Precharging times ranged between 0 and 50 days, and the SSR tests were performed at strain rates of $4 \times 10^{-6} \mathrm{~s}^{-1}$ and $5 \times 10^{-7} \mathrm{~s}^{-1}$. At the higher strain rate, only slight embrittlement was observed. More embrittlement was evident at the lower strain rate with PERs for specimens precharged for 1,3 , and 50 days all very close to 0.6 .
Even though the large number of experimental variables involved in these studies cause some divergent results, it is possible to make several general conclusions concerning the hydrogen embrittlement of Alloy 718 in a cathodic charging environment. Hydrogen charging has negligible effect on yield strength. As yield strength increases and strain rate decreases (at least over the range of strain rates discussed here), the hydrogen embrittlement susceptibility increases. As the presence of the $\delta$ phase increases, the hydrogen embrittlement susceptibility increases. When $\mathrm{H}_{2} \mathrm{SO}_{4}$ is the charging solution, severe embrittlement occurs during in situ testing, while precharging has less effect. In $\mathrm{NaCl}$ solutions, in situ charging causes only limited embrittlement, whereas precharging may cause more significant embrittlement.

Because of the importance of Alloy 718 in ocean-based oil and gas applications and the desire to use this alloy in a higher strength condition, the present work addressed the susceptibility of near-peak-aged Alloy 718 to hydrogen embrittlement in a substitute ocean water/cathodic charging environment. Because it has been shown that precharging may have a significant effect on the embrittlement of Alloy 718 in a seawater environment and relatively little work has been accomplished in this area, special emphasis was placed on relatively long precharges in a $\mathrm{NaCl}$ solution. Slow strain rate tests were accomplished on unprecharged and precharged specimens tested in air and substitute ocean water with in situ charging. The results were evaluated using performance ratios that compare the behavior in the test environment to the behavior of an unprecharged specimen tested in air. In addition, the fracture modes were analyzed using scanning electron microscopy.

\section{Experimental}

Cylindrical bars, $12.7 \mathrm{~mm}$ in diameter, of solution-annealed Alloy 718 were obtained with the composition shown in Table 1. Smooth cylindrical specimens were machined in accordance with NACE TM0198 (Ref 24). The diameters of the specimen gauge sections were initially oversized by 0.127 $\mathrm{mm}$ to allow for surface removal after heat treatment. Heat treating was accomplished by solutionizing at $976{ }^{\circ} \mathrm{C}$ for $30 \mathrm{~min}$ followed by quenching in oil to room temperature. A two-step precipitation hardening process was completed by first heating the specimens to $739^{\circ} \mathrm{C}$ for $8 \mathrm{~h}$, then furnace cooling the specimens to $635{ }^{\circ} \mathrm{C}$, and holding at that temperature for a total precipitation time of $18 \mathrm{~h}$. Specimens were then machined to the final dimensions shown in Fig. 1, and the gauge sections were ground to 1200 grit using successively finer grades of $\mathrm{SiC}$ paper. The microstructure of the heat-treated material was analyzed using an Olympus PME optical microscope, JEOL 
1200 transmission electron microscope (TEM), and JEOL 7400 and 6300 scanning electron microscopes (SEM).

The mechanical response of the alloy to hydrogen was examined by performing SSR tests in accordance with NACE TM0198 using an Instron 4505 mechanical testing system at a strain rate of $1 \times 10^{-6} \mathrm{~s}^{-1}$. SSR tests were conducted in air and substitute ocean water (SOW) at room temperature. The composition of the SOW is shown in Table 2 and was produced following ASTM Standard D 1141 (Ref 37). All the tests conducted in SOW took place in an environmental cell which enabled in situ charging. The environmental cell included ports for a motor and paddle to provide constant stirring, a dissolved oxygen meter, and cathodic charging electrodes. The in situ cathodic charging was accomplished using a Gamry 300 series potentiostat that applied $-1.1 V_{\mathrm{SCE}}$.

Several specimens were tested in the unprecharged (UPC) condition, and others were tested after being precharged with hydrogen for 4 or 16 weeks using a Wenking HP 72 potentiostat to apply a cathodic potential of $-1.1 V_{\mathrm{SCE}}$ in a 3.5 wt. $\%$ NaCl-distilled water solution at $50{ }^{\circ} \mathrm{C}$. After precharging, the specimens were stored in liquid nitrogen until just before SSR testing. Hardness tests obtained on coupons before and after nitrogen storage indicated that the nitrogen had no effect on the hardness of the metal. For ease of notation, the specimens precharged for 4 weeks will be termed "short precharge" or "SPC," and the specimens precharged for 16 weeks will be termed "long precharge" or "LPC." The depth of hydrogen penetration during precharging due to concentration gradient-driven lattice diffusion can be estimated with the expression $x=\sqrt{2 D t}$ where $\mathrm{x}$ is the penetration distance, $D$ the diffusion coefficient at $50{ }^{\circ} \mathrm{C}$, and $t$ the time (Ref 25, 38). Using $D=2.5 \times 10^{-11} \mathrm{~cm}^{2} \mathrm{~s}^{-1}$ (Ref 39), the predicted penetration depth for the 4 week precharge was $110 \mu \mathrm{m}$ and the depth for the 16 week precharge was $220 \mu \mathrm{m}$.

Analyses of the SSR tests were accomplished by calculating performance ratios in accordance with ASTM G129 (Ref 23). The calculated ratios are described in Table 3 , and the UPC specimen tested in air was used as the control environment. A lower ratio indicates a higher susceptibility to hydrogen embrittlement. To account for the variable time to remove backlash in the load system, the time to failure was calculated as the time from the initial stress value of $200 \mathrm{MPa}$ to the fracture point. The plastic elongation was calculated as the difference between the total strain at the yield point and the total strain at the fracture point. The yield point was determined by the $0.2 \%$ strain offset method. After testing, JEOL 7400 and 6300 scanning electron microscopes were used to study the fracture surfaces.

\section{Results}

The microstructure of the heat-treated Alloy 718 is shown in Fig. 2, 3 and 4. The optical micrograph of Fig. 2 shows the general microstructure. An average grain size of $28 \mu \mathrm{m}$ was measured using the linear intercept method. Some large particles on the order of $10 \mu \mathrm{m}$ are evident in the interiors of some grains. These particles were shown using EDS to be very rich in $\mathrm{Nb}$ and are probably $\mathrm{Nb}$ carbides (Ref 40). A TEM image of the heat-treated alloy is shown in Fig. 3. This image depicts the typical TEM contrast produced by a $\gamma$ matrix with $\gamma^{\prime}$ and $\gamma^{\prime \prime}$ precipitates (Ref 2). The SEM image in Fig. 4 shows some $\delta$ phase precipitates (identified with arrows) along the grain boundaries similar to those reported by Liu et al. (Ref 38); however, they do not form a continuous grain boundary phase. The hardness of the heat-treated material was $43 \mathrm{HRC}$, and using standard tensile testing methods, the $0.2 \%$ yield strength $\left(\sigma_{\mathrm{y}}\right)$ was $1197 \mathrm{MPa}$, and the ultimate tensile strength $\left(\sigma_{\mathrm{uts}}\right)$ was $1390 \mathrm{MPa}$.

The results of the SSR tests of the UPC Alloy 718 are shown in Fig. 5. Specimen 1 represents the UPC specimen tested in air, and specimens 2 and 3 represent the two UPC tests conducted in SOW with in situ charging. The SOW/in situ charging had no effect on the yield strength or ultimate tensile strength but caused a moderate reduction in strain to failure. The PERs for specimens 2 and 3 were 0.86 and 0.72 , respectively.

Table 2 Chemical composition of substitute ocean water

\begin{tabular}{llll}
\hline $\mathrm{NaCI}$ & $24.53 \mathrm{~g} / \mathrm{L}$ & $\mathrm{NaHCO}_{3}$ & 0.201 \\
$\mathrm{MgCl}_{2}$ & 5.20 & $\mathrm{KBr}$ & 0.101 \\
$\mathrm{NaSO}_{4}$ & 4.09 & $\mathrm{H}_{3} \mathrm{BO}_{3}$ & 0.027 \\
$\mathrm{CaCl}_{2}$ & 1.16 & $\mathrm{SrCl}_{2}$ & 0.025 \\
$\mathrm{KCl}$ & 0.695 & $\mathrm{NaF}$ & 0.003
\end{tabular}

All values given in $\mathrm{g} / \mathrm{L}$ of solution

Table 3 Definitions of the ratios used to compare the results of the various tests

\begin{tabular}{|c|c|}
\hline Ratio & Definition \\
\hline Time to failure ratio & $\frac{\text { Time to Failure in Test Environment }}{\text { Time to Failure in Control Environment }}$ \\
\hline Plastic elongation ratio & $\frac{\text { Plastic Elongation in Test Environment }}{\text { Plastic Elongation in Control Environment }}$ \\
\hline Reduction in area ratio & $\frac{\text { Reduction in Area in Test Environment }}{\text { Reduction in Area in Control Environment }}$ \\
\hline
\end{tabular}




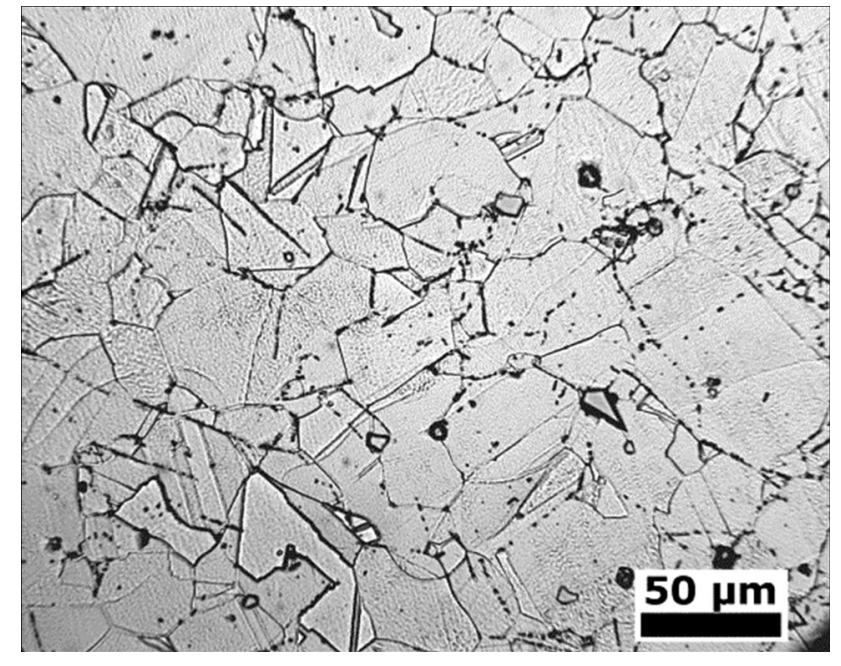

Fig. 2 Optical micrograph of the heat-treated Alloy 718

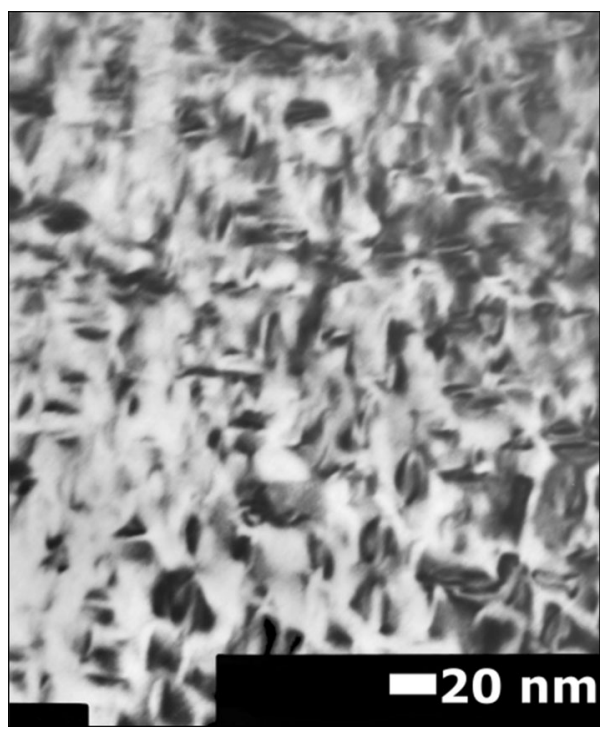

Fig. 3 Brightfield TEM image of the heat-treated Alloy 718

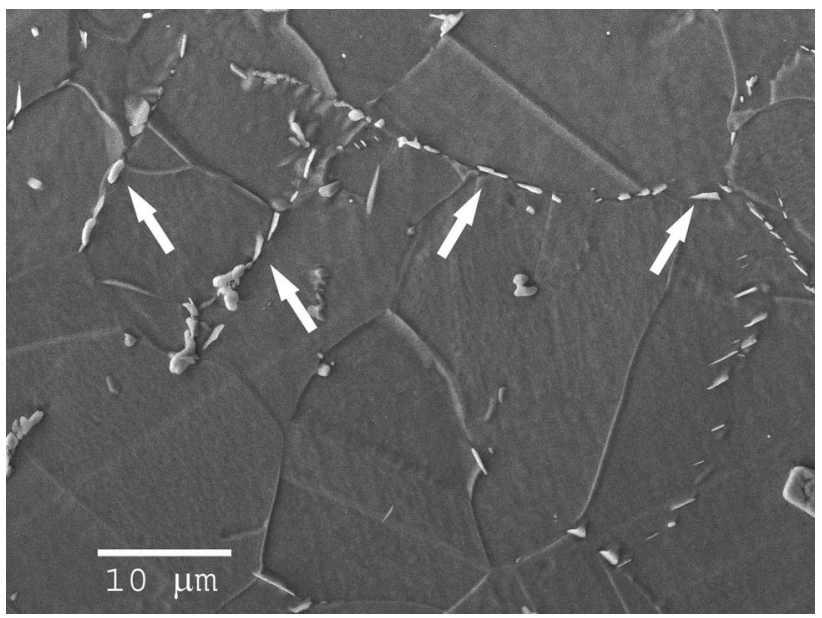

Fig. 4 SEM image showing $\delta$ phase (arrows) at grain boundary

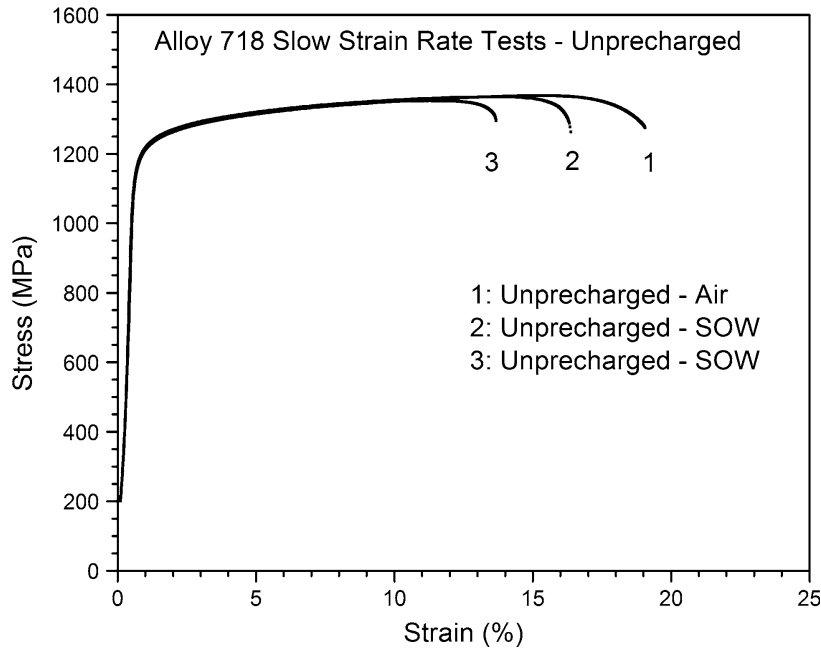

Fig. 5 Slow strain rate test results of unprecharged (UPC) Alloy 718 specimens

The results of the SSR tests of the SPC (4 week precharge) specimens are shown in Fig. 6. The UPC specimen tested in air (specimen 1) is also included for comparison. Specimen 4 represents the SPC specimen tested in air, and specimens 5 and 6 represent the two SPC tests conducted in SOW with in situ charging. Clearly, precharging with hydrogen for four weeks at $50{ }^{\circ} \mathrm{C}$ caused significant embrittlement of the material. However, testing the SPC specimens in SOW with in situ charging caused only a slight amount of additional embrittlement. The PER for the specimen that was only subjected to the SPC was 0.29 , and the average PER for the two specimens subjected to the SPC and in situ charging was 0.27 .

Figure 7 shows the results of the SSR tests of the LPC (16week) specimens along with the UPC specimen tested in air (specimen 1). These results are very similar to those observed for the SPC tests. The LPC caused slightly more embrittlement than the SPC. The PER for the LPC specimen tested in air was 0.26 , and the average PER of the LPC specimens tested in SOW and in situ charged was 0.23 . As with the SPC results, the additional in situ charging caused very little additional embrittlement.

The performance ratios for the Alloy 718 are tabulated in Table 4. These ratios reflect the observations based on the SSR curves discussed above. In the UPC condition, testing in SOW with in situ charging caused moderate embrittlement. For this condition, the performance ratios ranged between 0.70 and 0.81 . However, precharging and testing in SOW with in situ charging caused significant embrittlement with ratios ranging between 0.19 and 0.34 for the SPC and 0.18 and 0.30 for the LPC. The ratios for the precharged specimens tested in air were only slightly higher than those for the precharged specimens tested in SOW.

Fracture surfaces exhibited ductile central regions surrounded by embrittled outer rings of varying morphology depending on if the specimen was precharged or tested in SOW. Typical fracture surfaces are shown in the SEM micrographs of Fig. 8, 9, 10, and 11. Figure 8 shows the dimpled microvoid coalescence type of fracture surface associated with the ductile central region and the entire cross section for the hydrogen-free specimen (UPC tested in air). A fracture surface representative of the outer embrittled ring for the UPC specimens tested in 


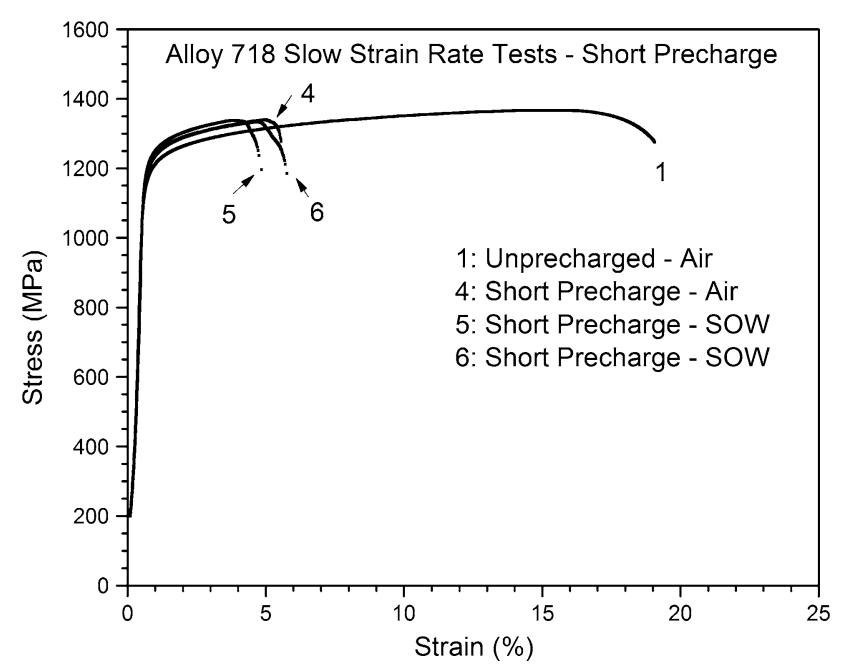

Fig. 6 Slow strain rate test results of short precharge (SPC) Alloy 718 specimens

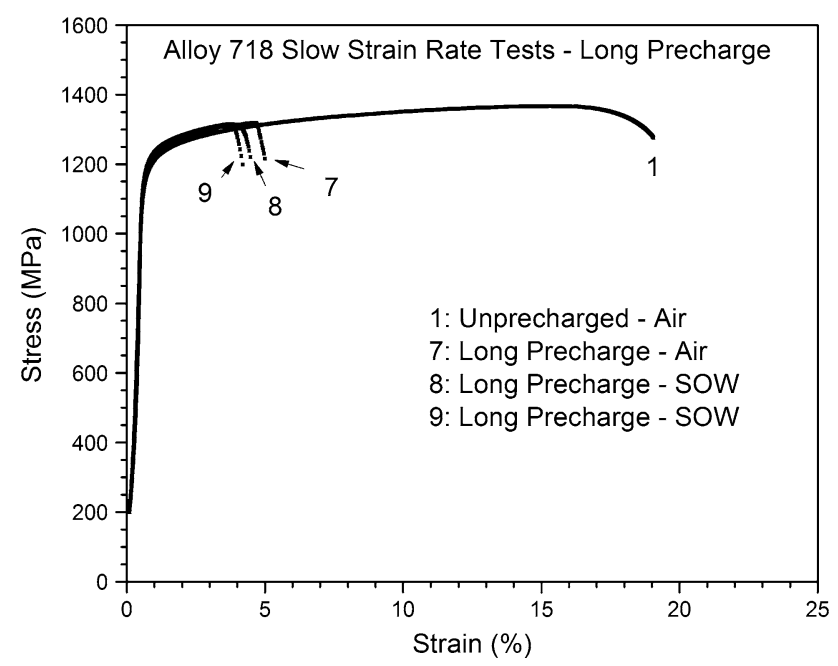

Fig. 7 Slow strain rate test results of long precharge (LPC) Alloy 718 specimens

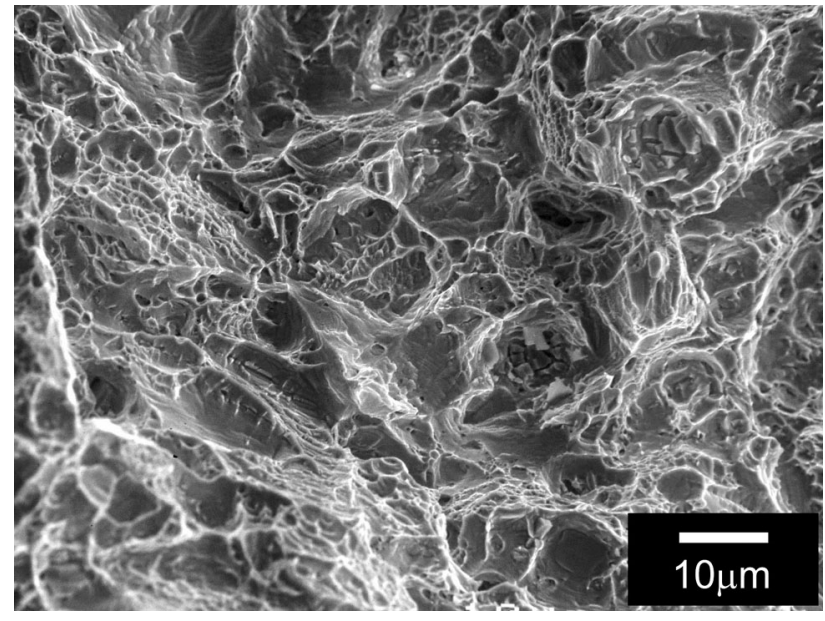

Fig. 8 SEM micrograph showing the dimpled fracture surface associated with the ductile central regions of the specimens

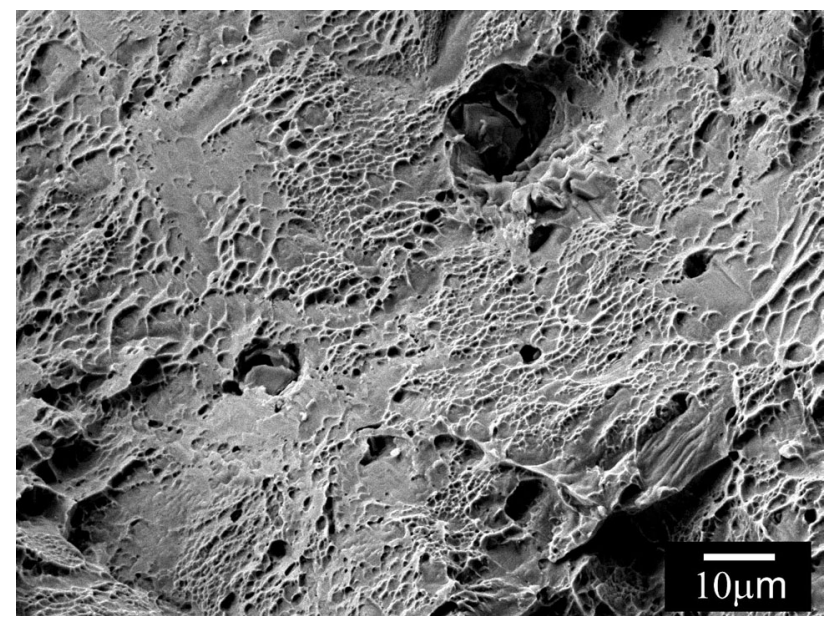

Fig. 9 SEM micrograph showing the fracture surface associated with the embrittled outer ring of UPC specimens tested in SOW

Table 4 Average performance ratios for the various SSR tests

\begin{tabular}{lcccc}
\hline Test condition & Specimen number & Average time to failure ratio & Average plastic elongation ratio & Average reduction in area ratio \\
\hline Air UPC & 1 & 1 & 1 & 1 \\
Air SPC & 4 & 0.36 & 0.29 & 0.43 \\
Air LPC & 7 & 0.33 & 0.26 & 0.24 \\
SOW UPC & $2 \& 3$ & 0.81 & 0.79 & 0.70 \\
SOW SPC & $5 \& 6$ & 0.34 & 0.27 & 0.19 \\
SOW LPC & $8 \& 9$ & 0.30 & 0.23 & 0.18 \\
\hline
\end{tabular}

SOW is shown in Fig. 9. The dimples are much less pronounced, and cracking and debonding of carbide particles can be seen in the figure.

Figures 10 and 11 depict the type of fracture surface that was found in the outer rings of precharged specimens. The fracture mode appears to be predominantly transgranular although there is some evidence of intergranular cracking. Hicks and Altstetter (Ref 40) identified the transgranular fracture facets as $\{111\}$ planes. Figure 11 also shows that there is some evidence of $\delta$ precipitation on fracture facets similar to what was observed by Galliano et al. (Ref 41) and would be expected through examination of the $\delta$ phase shown in Fig. 4. In addition, there are numerous voids on the fracture facets. The larger, more angular voids are probably areas where $\delta$ precipitates were pulled from the matrix by the opposite fracture surface. However, there are many much smaller planar voids oriented along slip bands. These voids are similar to the micro- and nano-voids identified by Zhang et al. (Ref 34) as the 


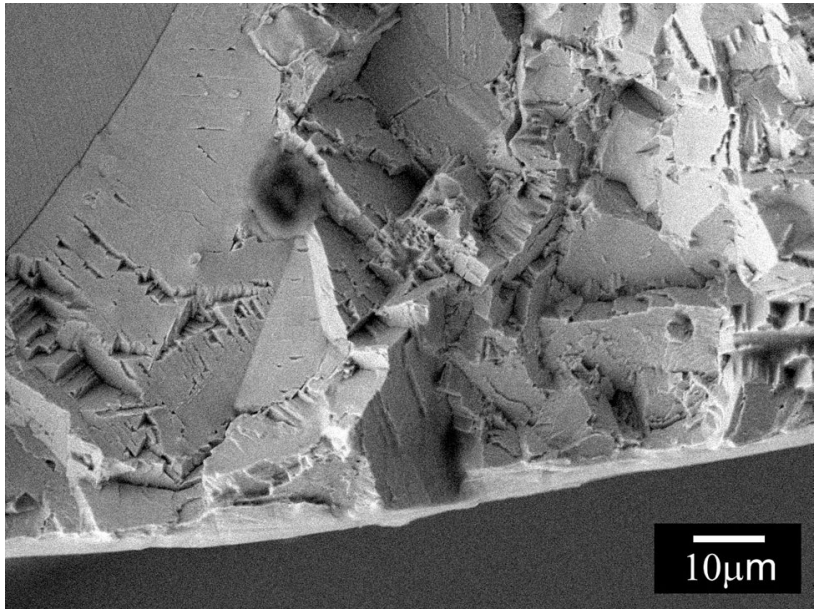

Fig. 10 SEM micrograph showing the fracture surface associated with the embrittled outer ring of a SPC specimen tested in air

precursors of crack initiation in hydrogen-charged Alloy 718 . The width of the brittle ring varied significantly around the circumference, but in SPC specimens the average width was about $200 \mu \mathrm{m}$, and in the LPC specimens, the average width was approximately $600 \mu \mathrm{m}$. In some areas between the brittle ring and the ductile central region, there was a transition zone that appeared similar to the fracture surface shown in Fig. 9. Generally, on the side from which the fatal crack propagated, this transition region extended an additional $250 \mu \mathrm{m}$ into the specimen.

\section{Discussion}

When analyzing the effects of hydrogen on metals, it is useful to consider whether the hydrogen entered the metal before deformation (internal hydrogen embrittlement) or was supplied during deformation (external hydrogen embrittlement) (Ref 25, 42, 43). Jewett et al. (Ref 42) first proposed these distinctions based on evidence that somewhat different mechanisms were responsible for the embrittlement in each. In the case of internal hydrogen embrittlement, during plastic deformation, hydrogen dissolved in the crystal lattice enhances dislocation motion on the active slip plane through the HELP mechanism. As long as the strain rate and temperature are such that the hydrogen atmosphere remains attached to the dislocation, the hydrogen will continue to enhance the slip (Ref 44). This effect is compounded by the effective lowering of the stacking fault energy of the alloy by the dissolved hydrogen and the shearing of precipitates on the active slip plane. Both of these effects cause further localization of slip and eventual failure on a facet that corresponds to the active slip plane, $\{111\}$ in the case of Alloy 718 (Ref 34, 40, 43). Some researchers have pointed out that although there is significant evidence of hydrogen-induced strain localization, the possibility that a decohesion mechanism also affects the embrittlement cannot be ruled out (Ref 34). For the case of external hydrogen embrittlement, the environment continuously supplies a source of hydrogen to near-surface dislocation sources or an advancing crack tip. Mobile dislocations draw hydrogen inward at a rate

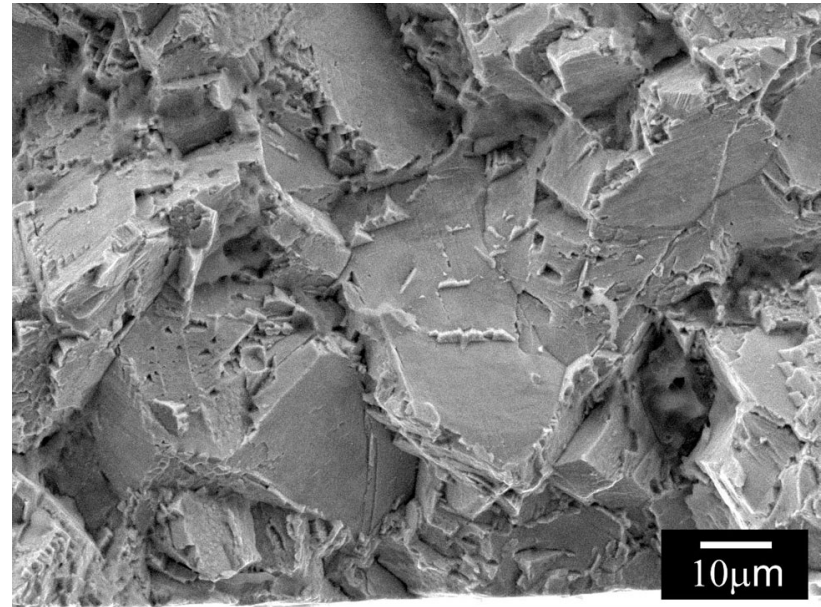

Fig. 11 SEM micrograph showing the fracture surface associated with the embrittled outer ring of a SPC specimen tested in SOW

significantly greater than that allowed by normal lattice diffusion ( $\operatorname{Ref} 25,45,46)$. The increased hydrogen concentration causes plastic strain localization and eventual failure through the mechanisms discussed previously.

For the present study, the SPC and LPC specimens tested in air represent internal hydrogen embrittlement. As noted earlier, the expected depth of hydrogen penetration due to concentration gradient-driven lattice diffusion during the precharging was 110 and $220 \mu \mathrm{m}$ for the SPC and LPC specimens, respectively. Those values are significantly lower than the observed depths of the brittle rings of 200 and $600 \mu \mathrm{m}$ for the SPC and LPC specimens, respectively. The discrepancies could be caused by electromigration, the enhanced lattice diffusivity of hydrogen due to electric field effects during cathodic

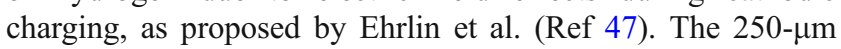
transition region between the brittle ring and the ductile central region probably represents an area where hydrogen was transported into the specimen beyond the limit of lattice diffusion by dislocation motion (Ref 48). Therefore, precharging and subsequent plastic deformation caused a large portion of the cross section to be infused with hydrogen, resulting in significant embrittlement. These results on precharged specimens compare favorably with the work of Zhang et al. (Ref 34) that was accomplished under similar experimental conditions. They observed slightly less embrittlement, but that can be attributed to the lower yield strength of their alloy (900 versus $1197 \mathrm{MPa})$.

The UPC specimens tested in SOW represent the case of external hydrogen embrittlement. In this case, hydrogen ingress can only occur through diffusion during the test and transport of hydrogen into the specimen by dislocation motion (Ref 44, 45) as discussed previously. Because the test duration was relatively short $(\approx 48 \mathrm{~h})$, during the in situ charging, the exposure of the metal to hydrogen was quite limited. Using a value of $48.63 \mathrm{~kJ} \mathrm{~mol}^{-1}$ for the activation energy of hydrogen diffusion in Alloy 718 (Ref 49), the diffusion coefficient at room temperature is estimated to be $3.9 \times 10^{-12} \mathrm{~cm}^{2} \mathrm{~s}^{-1}$. Accounting only for concentration gradient-driven lattice diffusion, the hydrogen penetrated to a depth of approximately $12 \mu \mathrm{m}$. Even including the possible effects of electromigration, the penetration depth would still be expected to be very low. Transport of hydrogen into the specimen by dislocation motion also 
appeared to be quite low. The fracture surface of the outer brittle ring was characterized by a fine dispersion of shallow dimples as shown in Fig. 9. Hicks and Altstetter (Ref 40) observed this type of fracture surface in Alloy 718 that contained 8 wppm (weight parts per million) hydrogen. At that concentration, the alloy exhibited only slight embrittlement. As a result, due to the limited ingress of hydrogen, the UPC specimens charged in situ in SOW exhibited only a small amount of embrittlement. This result agrees with previous studies on Alloy 718 where the charging electrolyte was a $3.5 \%$ $\mathrm{NaCl}$ solution (Ref 33) but disagrees with previous studies where $\mathrm{H}_{2} \mathrm{SO}_{4}$ was used as the charging electrolyte (Ref 25, 29, $30)$. While the hydrogen fugacity is affected by many factors such as applied potential, temperature, surface deposits, and recombinant poisons, it would be expected that, under reasonably similar conditions, $\mathrm{H}_{2} \mathrm{SO}_{4}$ would produce a higher fugacity than SOW. It appears that for this mechanism to have a significant effect, the hydrogen fugacity must exceed some threshold value.

\section{Conclusions}

The hydrogen embrittlement susceptibility of cathodically charged near-peak-aged Alloy 718 was studied by accomplishing slow strain rate tests and fractographic studies on specimens that were hydrogen-free and specimens that were cathodically charged in 3.5 wt.\% NaCl and/or substitute ocean water. From the results of the work, the following conclusions can be made in regard to the testing conditions presented in this research:

1. Hydrogen-free Alloy $718\left(\sigma_{\mathrm{ys}}=1197 \mathrm{MPa}\right)$ exhibits significant ductility. Plastic strain to fracture is about $20 \%$, and the entire fracture surface exhibits a ductile dimpled microvoid coalescence fracture mode.

2. When only external hydrogen is present, i.e., the unprecharged specimen is charged in situ during the slow strain rate test, only moderate embrittlement is observed. Plastic strain to fracture decreases about $20 \%$. The fracture surface in the outer ring that was affected by the hydrogen exhibits a less ductile appearance in that the dimples are less distinct and more refined.

3. When only internal hydrogen is present, i.e., the precharged specimen is tested in air, significant embrittlement is observed. Plastic strain to fracture decreases by about $72 \%$. The length of the precharge (4 versus 16 weeks) has very little effect on the response. The fracture surface in the hydrogen affected outer ring exhibits predominantly a brittle transgranular fracture mode.

4. When both internal and external hydrogen are present, i.e., the precharged specimen is charged in situ during slow strain rate testing, there is slightly more embrittlement than in the internal hydrogen only condition. Plastic strain to fracture decreases by about $75 \%$, and the fracture surface exhibits the characteristics of the internal hydrogen only condition summarized above.

5. In lower fugacity electrolytes such as SOW, SSR testing with in situ only charging does not reveal the hydrogen embrittlement susceptibility of Alloy 718. Significant embrittlement is evident only when the metal is precharged.

\section{Acknowledgments}

The authors gratefully acknowledge the support of this research by GE Oil and Gas.

\section{References}

1. R.L. Kennedy, W. Cao, and W.M. Thomas, Stress Rupture Strength of Alloy 718, Adv. Mater. Process., 1996, 149(3), p 33-35

2. D.F. Paulonis, J.M. Oblak, and D.S. Duvall, Precipitation in NickelBase Alloy 718, Trans. ASM, 1969, 62, p 611-622

3. Y. Rong, S. Chen, G. Hu, M. Gao, and R.P. Wei, Prediction and Characterization of Variant Electron Diffraction Patterns for $\gamma^{\prime \prime}$ and $\delta$ Precipitates in an Inconel 718 Alloy, Metall. Mater. Trans. A, 1999, 30A, p 2297-2303

4. O.A. Onyewuenyi, Alloy 718 -Alloy Optimization for Applications in Oil and Gas, Superalloy 718-Metallurgy and Applications, E.A. Loria, Ed., The Minerals, Metals, \& Materials Society, 1989, p 345362

5. J.J. Debarbadillo and S.K. Mannan, Alloy 718 for Oilfield Applications, JOM, 2012, 64(2), p 265-270

6. F. Pires, R. Clements, F. Santos, J. Clevelario, and T. Sheldrake, Evaluation of the Performance of Inconel 718 Fasteners Subjected to Cathodic Protection Systems in Offshore and Subsea Applications-OMAE2011-49242, Proceedings of the ASME 2011 30th International Conference on Ocean, Offshore, and Arctic Engineering, vol. 3, June 19-24, 2011, ASME, 2011, p 165-172

7. G. Rorvik, B.O. Haaland, and F. Kirkemo, Fasteners in Subsea Applications-End User Experiences and Requirements-OMAE2014-24520, Proceedings of the ASME 2014 33rd International Conference on Ocean, Offshore, and Arctic Engineering, vol. 5, June 8-13, 2014, ASME, 2014. doi:10.1115/OMAE2014-24520

8. W.H. Johnson, On Some Remarkable Changes Produced in Iron and Steel by the Action of Hydrogen and Acids, Proc. R. Soc. Lond., 1875, 23, p 168-179

9. I.M. Robertson, P. Sofronis, A. Nagao, M.L. Martin, S. Wang, D.W. Gross, and K.E. Nygren, Hydrogen Embrittlement Understood, Metall. Mater. Trans. B, 2015, 46, p 1085-1103

10. W.W. Gerberich, Modeling Hydrogen Induced Damage Mechanisms in Metals, Gaseous Hydrogen Embrittlement of Materials in Energy Technologies, vol. 1, R.P. Gangloff and B.P. Somerday, Eds., Woodhead Publishing, 2012, p 209-246

11. M. Dadfarnia, A. Nagao, S. Wang, M.L. Martin, B.P. Somerday, and P. Sofronis, Recent Advances on Hydrogen Embrittlement of Structural Materials, Int. J. Fract., 2015, 196, p 223-243

12. A.R. Troiano, The Role of Hydrogen and Other Interstitials in the Mechanical Behavior of Metals, Trans. ASM, 1960, 52, p 54-80

13. R.A. Oriani, A Mechanistic Theory of Hydrogen Embrittlement of Steels, Ber. Bunsen-Ges., 1972, 76(8), p 848-857

14. W.W. Gerberich and Y.T. Chen, Hydrogen Controlled Cracking-An Approach to Threshold Stress Intensity, Metall. Trans. A, 1975, 6A, p 271-278

15. C.D. Beachem, A New Model For Hydrogen-Assisted Cracking (Hydrogen "Embrittlement"), Metall. Trans., 1972, 3, p 437-451

16. I.M. Robertson and H.K. Birnbaum, An HVEM Study of Hydrogen Effects on the Deformation and Fracture of Nickel, Acta Metall., 1986, 34(3), p 353-366

17. S. Wang, M.L. Martin, I.M. Robertson, and P. Sofronis, Effect of Hydrogen Environment on the Separation of Fe Grain Boundaries, Acta Mater., 2016, 107, p 279-288

18. T. Matsumoto, J. Eastman, and H.K. Birnbaum, Direct Observations of Enhanced Dislocation Mobility Due to Hydrogen, Scr. Metall., 1981, 15, p 1033-1037

19. H.K. Birnbaum and P. Sofronis, Hydrogen-Enhanced Localized Plasticity-A Mechanism for Hydrogen-Related Fracture, Mater. Sci. Eng. A, 1994, A176, p 191-202

20. T. Tabata and H.K. Birnbaum, Direct Observations of the Effect of Hydrogen on the Behavior of Dislocations in Iron, Scr. Metall., 1983, 17, p 947-950

21. D.S. Shih, I.M. Robertson, and H.K. Birnbaum, Hydrogen Embrittlement of $\alpha$ Titanium, In Situ TEM Stud. Acta Metall., 1988, 33, p 111124 
22. H. Hanninen, T.C. Lee, I.M. Robertson, and H.K. Birnbaum, In-Situ Observations on Effects of Hydrogen on Deformation and Fracture of A533B Pressure-Vessel Steel, J. Mater. Eng. Perform., 1993, 2(6), p $807-817$

23. Standard Practice for Slow Strain Rate Testing to Evaluate the Susceptibility of Metallic Materials to Environmentally Assisted Cracking, ASTM G129 (2013), ASTM International

24. Slow Strain Rate Test Method for Screening Corrosion-Resistant Alloys for Stress Corrosion Cracking in Sour Oilfield Service, NACE TM0198 (2011), NACE International

25. L. Fournier, D. Delafosse, and T. Magnin, Cathodic Hydrogen Embrittlement in Alloy 718, Mater. Sci. Eng., A, 1999, A269, p 111119

26. S.A. McCoy, S.K. Mannan, and C.S. Tassen, The Effect of Hydrogen on Precipitation Hardenable Nickel Alloys for Downhole Applications, SPE International Oilfield Corrosion Conference and Exhibition, 9-10 May, Aberdeen, Scotland, UK, 2016, SPE-179917

27. M.C. Rezende, L.S. Araujo, S.B. Gabriel, D.S. dos Santos, and L.H. de Almeida, Hydrogen Embrittlement in Nickel-Based Superalloy 718 : Relationship Between \& $\gamma^{\prime}+\gamma^{\prime \prime}$ Precipitation and the Fracture Mode, Int. J. Hydrog. Energy, 2015, 40, p 17075-17083

28. Nickel Base Alloy 718 (UNS N07718) for Oil and Gas Drilling Production Equipment, API Standard 6A718, 2nd ed., 2009, American Petroleum Institute

29. Z. Tarzimoghadam, D. Ponge, J. Kloewer, and D. Raabe, HydrogenAssisted Failure in Nickel-Based Superalloy 718 Studied Under In Situ Hydrogen Charging: The Role of Localized Deformation in Crack Propagation, Acta Mater, 2017, 128, p 365-374

30. B. Kagay, K. Findley, S. Coryell, and A.B. Nissan, Effects of Alloy 718 Microstructure on Hydrogen Embrittlement Susceptibility for Oil and Gas Environments, Mater. Sci. Technol., 2016. doi:10.1080/02670 836.2016.1139225

31. Age-Hardened Nickel-Based Alloys for Oil and Gas Drilling and Production Equipment, API Standard 6ACRA, 1st ed., 2015, American Petroleum Institute

32. L. Foroni and C. Malara, Hydrogen Embrittlement Susceptibility of Precipitation Hardened Ni-Alloys, NACE International Corrosion Conference and Expo, 2014, NACE Paper 3948

33. S.J. Kernion, J.H. Magee, K.A. Heck, and T.N. Werley, The Effect of Microstructure and Processing on the Hydrogen Embrittlement of Nibase Superalloys, NACE International Corrosion Conference and Expo, 2015, NACE Paper 6053

34. Z. Zhang, G. Obasi, R. Morana, and M. Preuss, Hydrogen Assisted Crack Initiation and Propagation in a Nickel-Based Superalloy, Acta Mater., 2016, 113, p 272-283
35. S. Jothi, S.V. Merzlikin, T.N. Croft, J. Andersson, and S.G.R. Brown, An Investigation of Micro-Mechanisms in Hydrogen Induced Cracking in Nickel-Based Superalloy 718, J. Alloys Compd., 2016, 664, p 664681

36. B.C. Rollins, R. Thodla, M.T. Piza Paes, and C.J. Carlton, Development of Test Methodology to Evaluate High Strength Nickel Based Alloys Under Cathodic Protection, NACE International Corrosion Conference and Expo, 2016, NACE Paper 7828

37. Standard Practice for the Preparation of Substitute Ocean Water, ASTM Standard D 1141 (2013), ASTM International

38. L. Liu, K. Tanaka, A. Hirose, and K.F. Kobayashi, Effects of Precipitation on the Hydrogen Embrittlement Sensitivity of Inconel 718, Sci. Technol. Adv. Mater., 2002, 3, p 335-344

39. J.J.M. Jebaraj, D.J. Morrison, and I.I. Suni, Hydrogen Diffusion Coefficients Through Inconel 718 in Different Metallurgical Conditions, Corros. Sci., 2014, 80, p 517-522

40. P.D. Hicks and C.J. Altstetter, Internal Hydrogen Effects on Tensile Properties of Iron- and Nickel-Base Superalloys, Metall. Trans. A, 1990, 21A, p 365-372

41. F. Galliano, E. Andrieu, C. Blanc, J.M. Cloue, D. Connetable, and G. Odemer, Effect of Trapping and Temperature on the Hydrogen Embrittlement Susceptibility of Alloy 718, Mater. Sci. Eng. A, 2014, 611, p 370-382

42. R.P. Jewett, R.J. Walter, W.T. Chandler and R.P. Frohmberg, Hydrogen Environment Embrittlement of Metals, NASA CR-2163, 1973

43. P.D. Hicks and C.J. Altstetter, Hydrogen-Enhanced Cracking of Superalloys, Metall. Trans. A, 1992, 23A, p 237-248

44. J.K. Tien, A.W. Thompson, I.M. Bernstein, and R.J. Richards, Hydrogen Transport by Dislocations, Metall. Trans. A, 1976, 7A, p $821-829$

45. P. Bastien and P. Azou, Effect of Hydrogen on the Deformation and Fracture of Iron and Steel in Simple Tension, Proceedings World Metallurgical Congress, American Society for Metals, 1951, p 535-552

46. M. Dadfarnia, M.L. Martin, A. Nagao, P. Sofronis, and I.M. Robertson, Modeling Hydrogen Transport by Dislocations, J. Mech. Phys. Solids, 2015, 78, p 511-525

47. N. Ehrlin, C. Bjerken, and M. Fisk, Cathodic Hydrogen Charging of Inconel 718, AIMS Mater. Sci., 2016, 3, p 1350-1364

48. D. Delafosse and T. Magnin, Hydrogen Induced Plasticity in Stress Corrosion Cracking of Engineering Systems, Eng. Fract. Mech., 2001, 68, p 693-729

49. J. Xu, X.K. Sun, Q.Q. Liu, and W.X. Chen, Hydrogen Permeation Behavior in IN718 and GH761 Superalloys, Metall. Mater. Trans. A, 1994, 25A, p 539-544 